\title{
HIV and AIDS in the European Union, 2011
}

G Likatavicius (Giedrius.Likatavicius@ecdc.europa.eu) ${ }^{1}$, M Van de Laar $^{1}$

1. European Centre for Disease Prevention and Control (ECDC), Stockholm, Sweden

Citation style for this article:

Likatavicius G, Van de Laar M. HIV and AIDS in the European Union, 2011. Euro Surveill. 2012;17(48):pii=20329. Available online: http://www.eurosurveillance.org/ ViewArticle.aspx?Articleld $=20329$

Article submitted on 23 November / published on 29 November 2012

In 2011, a total of 28,038 new HIV diagnoses were reported by European Union and European Economic Area countries. The annual rate of HIV diagnoses does not show clear signs of decrease and HIV continues to be concentrated in selected populations such as men who have sex with men and injecting drug users, and a high proportion reported as late presenters. Despite effective and available antiretroviral treatment, the number of AIDS cases increased in a few countries.

\section{HIV diagnoses}

Since 2008, the European Centre for Disease Prevention and Control (ECDC) has been coordinating enhanced HIV/AIDS surveillance for the European Union (EU) and European Economic Area (EEA). Data are submitted annually to the European surveillance system (TESSy) in standardised datasets for HIV and AIDS.

In the EU/EEA, 28,038 HIV infections were diagnosed in 2011 and reported by 29 EU/EEA countries, a rate of 6.3 per 100,000 population when adjusted for reporting delay [1]. The overall rate for men was 8.7 per 100,000 population and 2.8 per 100,000 population for women. The highest rates (per 100,000 population) were observed in Estonia (27.3), Latvia (13.4), Belgium (10.7) and the United Kingdom (10.0). The lowest rates were reported by the Czech Republic (1.5) and Slovakia (0.9). Some $11 \%$ of HIV infections were reported among young people aged $15^{-24}$ years and $25 \%$ were female. The overall male-to-female ratio was 3.0 and highest in Slovakia (15.3), Hungary (11.1), Czech Republic (10.8) and Slovenia (6.9) (Figure 1).

Men who have sex with men (MSM) accounted for $39 \%$ of new HIV diagnoses $(n=10,885)$ in 2011 in the EU/EEA (38\% in 2010 [2]; $35 \%$ in 2009 [3]). MSM accounted for more than $50 \%$ of the cases in nine countries and more than $30 \%$ in another eight countries. Heterosexual transmission accounted for $36 \%$ of the HIV infections $(n=10,118)$ : more than a third of those cases originated from sub-Saharan Africa countries with a generalised HIV epidemic. More than half of the heterosexually acquired HIV infections in Belgium, Sweden, United Kingdom, Ireland and Norway were reported in persons originating from sub-Saharan Africa. There were 4,384 HIV cases $(16 \%)$ reported in persons from sub-Saharan
Africa in total: they were over-represented in the following transmission modes, as shown in the Table: heterosexual contacts (37\%) and mother-to-child transmission $(46 \%)$. Only $5 \%(n=1,516)$ of HIV diagnoses were reported in injecting drug users (IDU). Injecting drug use as predominant mode of transmission was reported in only two countries: Lithuania and Iceland. IDU accounted for $25 \%$ or more of the cases in Bulgaria, Greece, Latvia and Romania. Of the remaining 297 cases with reported transmission mode, 222 (1\%) were classified as due to mother-to-child transmission and 75 (0.3\%) due to transfusion of blood or its products and nosocomial transmission.

\section{Trends in HIV diagnoses}

Among the $29 \mathrm{EU} / \mathrm{EEA}$ countries that have consistently reported HIV data since 2004 (no data from Liechtenstein), the rate of HIV cases per 100,000 population has been relatively stable, despite a slight decrease from 6.5 in 2004 to 6.3 in 2011 when adjusted for reporting delay. In recent years, more than 27,000 cases were diagnosed and reported each year, resulting in a cumulative number of over 420,000 cases reported since the beginning of the HIV reporting (Figure 2). Since 2004, the number of national annual HIV diagnoses has tripled in Bulgaria, Iceland and Slovakia and has increased by more than $50 \%$ in Cyprus, Czech Republic, Greece, Hungary, Romania and Slovenia.

Since 2004, 25 EU/EEA countries have consistently reported HIV cases by transmission mode (Estonia, Poland, Italy and Spain were excluded; no data from Liechtenstein). The overall number of reported cases among MSM increased by $22 \%$ between 2004 and 2011; an increase of more than $100 \%$ was observed in Cyprus, Hungary, Czech Republic, Ireland, Latvia, Slovakia and Slovenia. The total number of annually reported heterosexually acquired cases ranged from 4,300 to 5,300 during 2004 to 2011 . The number of cases originating from sub-Saharan African countries decreased by $54 \%$ $(6,874$ in 2004 to 3,159 in 2011). In most countries, the numbers reported among IDU were low or decreasing. However, in 2011, a substantial increase was reported: Greece reported 245 cases as compared with 22 in 2010, and Romania 108 cases versus nine in 2010. In several other countries, Bulgaria, Latvia and Iceland, 


\section{FIGURE 1}

Male-to-female ratio in HIV infections by country, European Union/European Economic Area countries, 2011 (n=27,963) ${ }^{\mathrm{a}}$

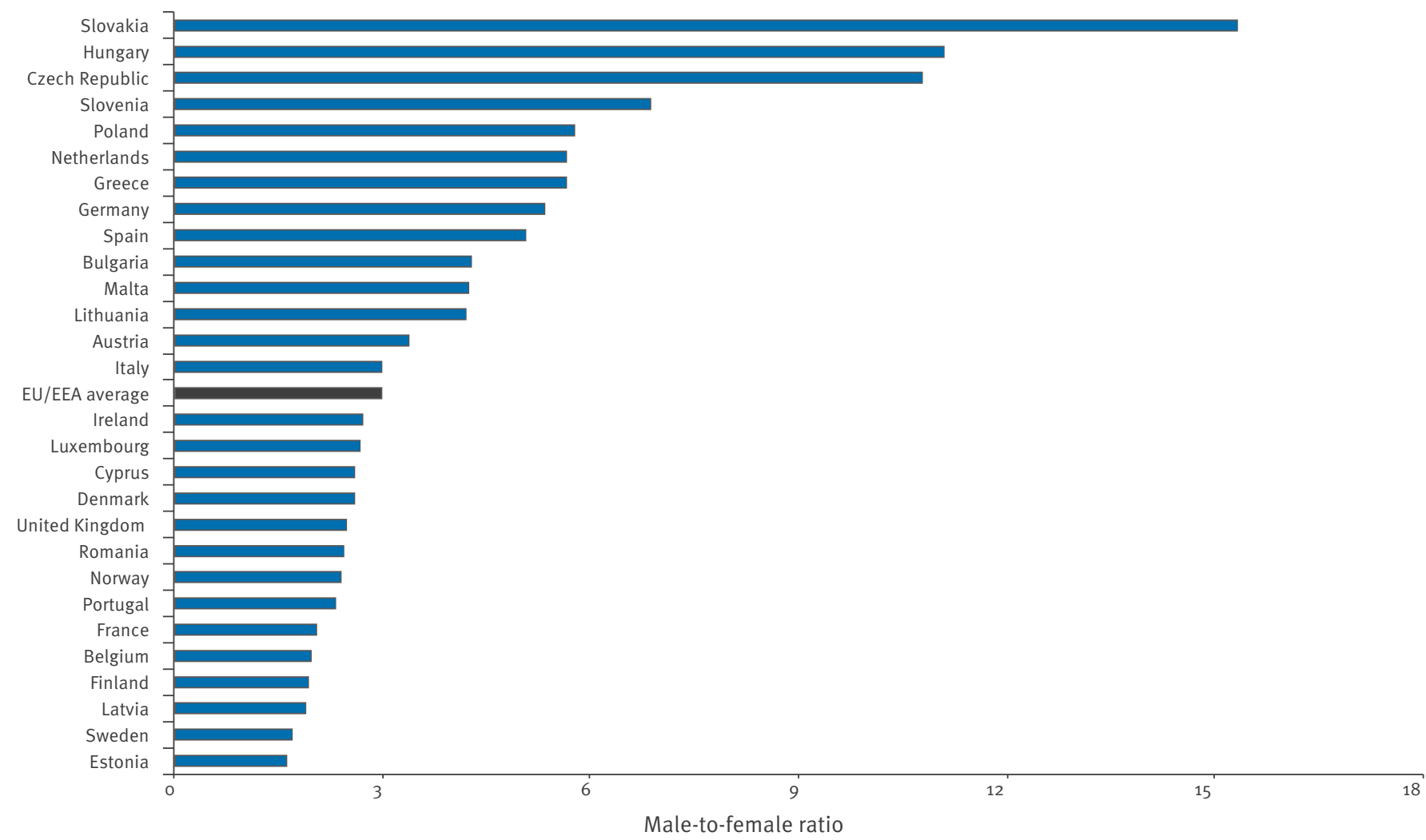

EEA: European Economic Area; EU: European Union.

${ }^{a}$ Information on sex or country not available for 75 persons.

Source: [1].

\section{TABLE}

Reported HIV diagnoses, including those originating from sub-Saharan African countries with a generalised HIV epidemic, by transmission mode, European Union/European Economic Area countries, $2011(\mathrm{n}=28,038)$

\begin{tabular}{|c|c|c|c|c|c|c|c|}
\hline \multirow[b]{2}{*}{$\begin{array}{l}\text { Reported HIV } \\
\text { diagnoses }^{\mathrm{a}}\end{array}$} & \multicolumn{6}{|c|}{ Mode of transmission } & \multirow[b]{2}{*}{ Total } \\
\hline & $\begin{array}{l}\text { Heterosexual } \\
\text { contacts }\end{array}$ & $\begin{array}{l}\text { Injecting } \\
\text { drug use }\end{array}$ & $\begin{array}{l}\text { Sex } \\
\text { among } \\
\text { MSM }\end{array}$ & МTCT & $\begin{array}{l}\text { Nosocomial } \\
\text { and } \\
\text { transfusion }\end{array}$ & Unknown & \\
\hline $\begin{array}{l}\text { HIV infections } \\
\text { originating from } \\
\text { countries of } \\
\text { sub-Saharan Africa (\%) }\end{array}$ & $\begin{array}{c}3,744 \\
(37.0 \%)\end{array}$ & $\begin{array}{c}27 \\
(1.8 \%)\end{array}$ & $\begin{array}{c}143 \\
(1.3 \%)\end{array}$ & $\begin{array}{c}103 \\
(46.4 \%)\end{array}$ & $\begin{array}{c}19 \\
(25 \cdot 3 \%)\end{array}$ & $\begin{array}{c}348 \\
(6.6 \%)\end{array}$ & $\begin{array}{c}4,384 \\
(15.6 \%)\end{array}$ \\
\hline Total number of cases & 10,118 & 1,516 & 10,855 & 222 & 75 & 5,252 & 28,038 \\
\hline
\end{tabular}

MSM: men who have sex with men; MTCT: mother-to-child transmission.

a In many European countries, migrants from countries with generalised HIV epidemics comprise a high proportion of reported cases. As a proxy, HIV diagnoses in persons originating from sub-Saharan Africa are chosen.

Source: [1]. 
HIV diagnoses reported annually and cumulative totals, European Union/European Economic Area countries, 1984-2011

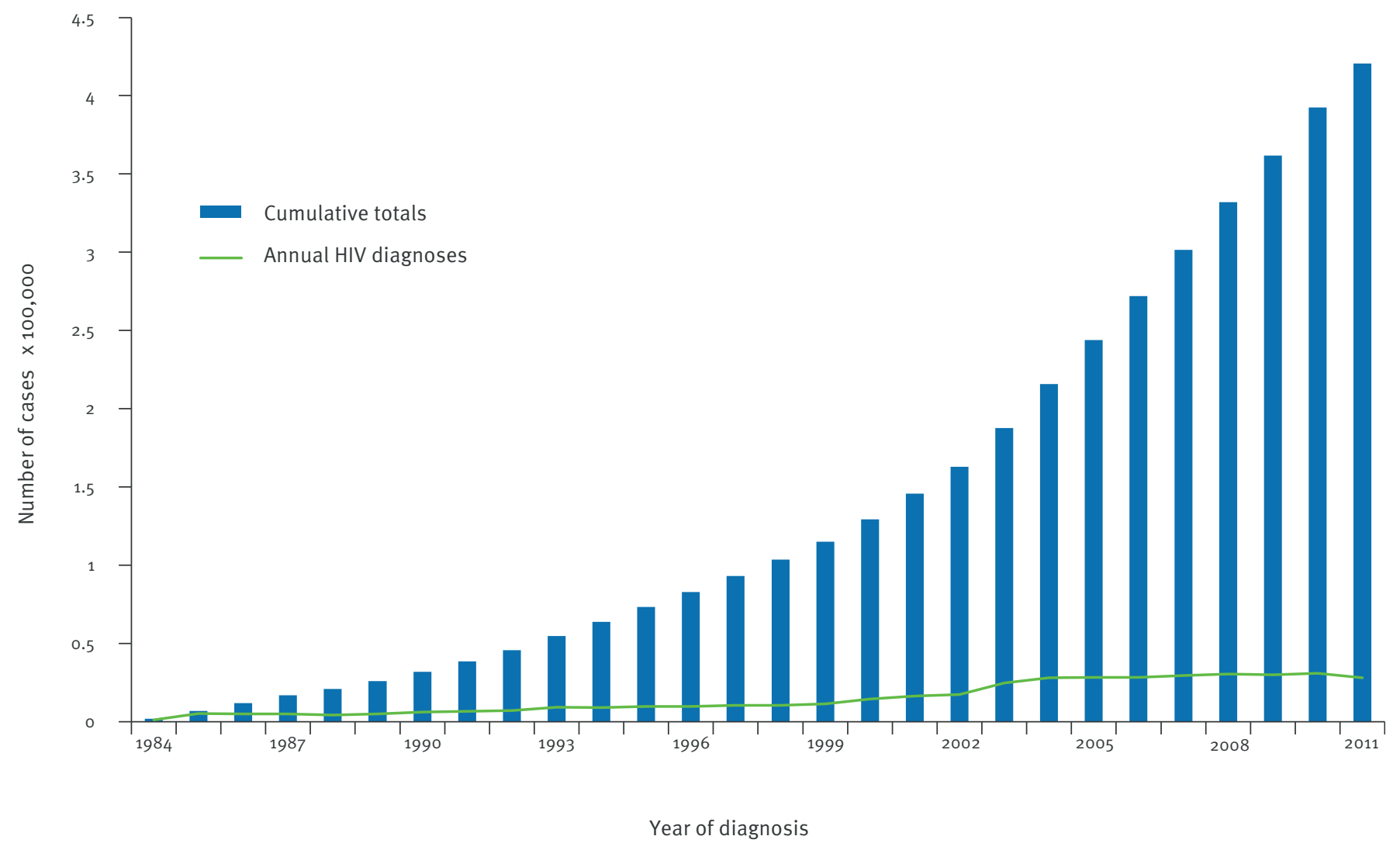

Source: [1].

\section{FIGURE 3}

Reported HIV diagnoses by transmission mode and year of diagnosis, adjusted for reporting delay,

European Union/European Economic Area countries, 2004-2011

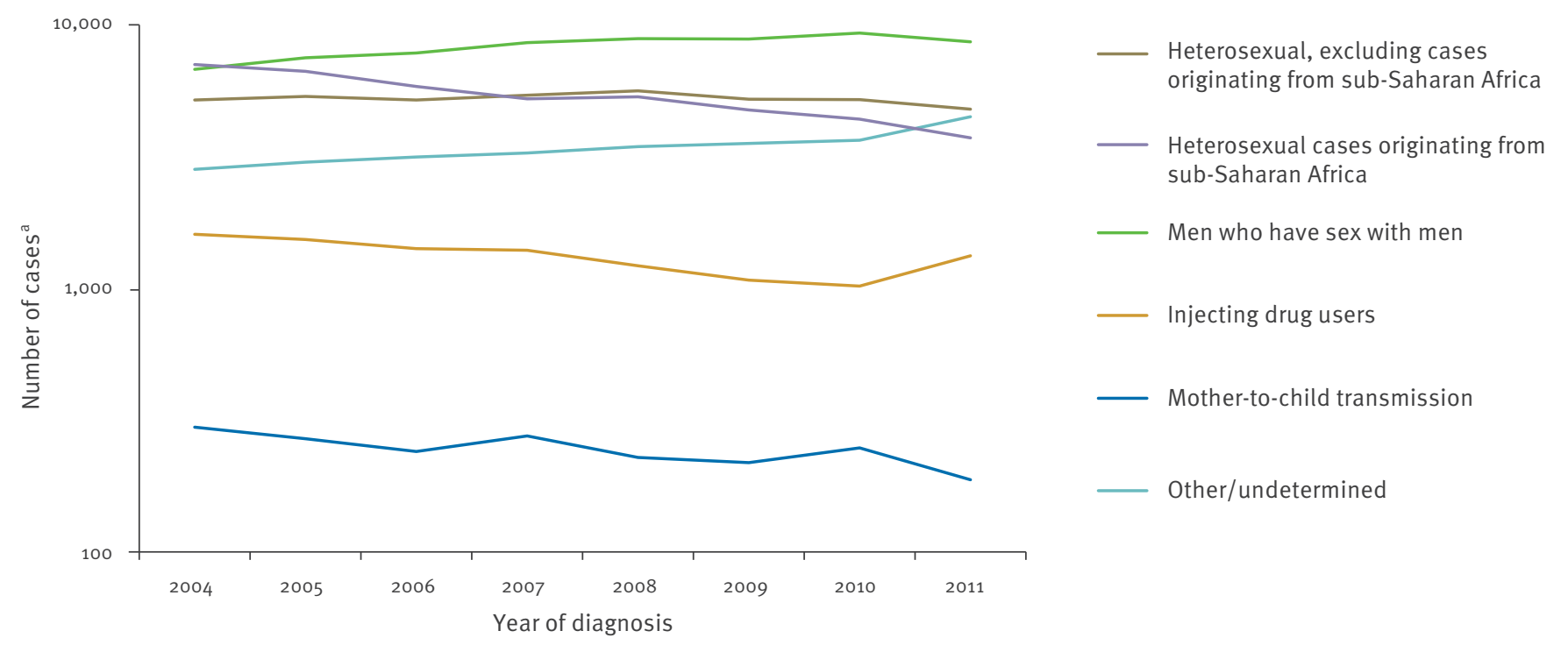

a Semi-logarithmic scale.

Source: [1]. 
a more gradual increase in HIV cases in IDU was noted over the last two to three years. The number of cases transmitted from mother to child decreased by $36 \%$, from 295 in 2004 to 188 in 2011 . The number of cases with unknown transmission mode increased by $30 \%$, from 2,773 in 2004 to 3,611 in 2011 (Figure 3). It has to be acknowledged that there are reporting delays for a number of countries, which limit the interpretation of the trends in the most recent years. Reporting delay affects all transmission modes consistently and adjusting for delay results in an increase of $4-10 \%$ in the number of reported cases for 2011.

\section{AIDS diagnoses}

In 2011, a total of 4,424 AIDS diagnoses were reported by $28 \mathrm{EU} / \mathrm{EEA}$ countries (no data from Sweden or Liechtenstein), a rate of 0.9 per 100,000 population. The highest rates (per 100,000 population) were reported by Estonia (2.8), Latvia (4.8), Portugal (2.8) and Spain (1.8). In these EU/EEA countries, an overall $33 \%$ decline was observed, from 9,195 cases (1.9 per 100,000 population) in 2004 to 4,424 (0.9 per 100,000 population) in 2011, although there is a considerable reporting delay and under-reporting for the most recent years. The number of AIDS diagnoses decreased in the majority of the countries, but since 2004, an increase of more than $20 \%$ was observed in Bulgaria (81\%), Czech Republic (77\%), Estonia (31\%), Hungary (39\%) and Slovenia (50\%).

\section{FIGURE 4}

Percentage of HIV cases with a CD4 cell count $<350 / \mathrm{mm}^{3}$ and $<200 / \mathrm{mm}^{3}$ by transmission mode, European Union/ European Economic Area countries, $2011(n=15,625)$

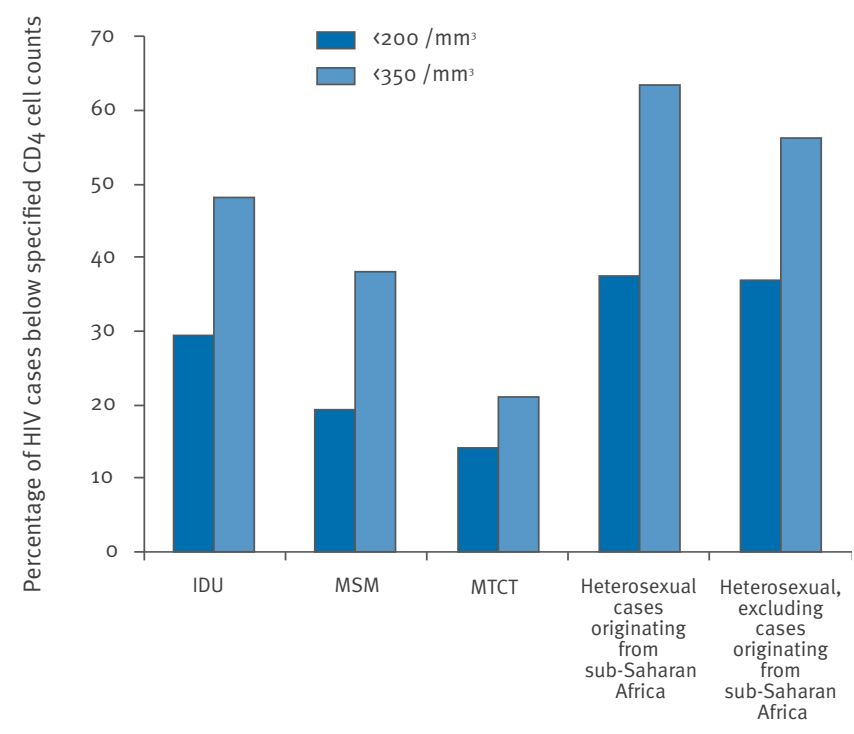

IDU: injecting drug users; MSM: men who have sex with men; MTCT: mother-to-child transmission.

\section{Late presenters}

Late presenters are defined as persons with a CD4 cell count less than $350 / \mathrm{mm}^{3}$ at the time of HIV diagnosis. CD4 cell counts were available for 15,625 HIV diagnoses (56\%) in adults and adolescents reported in 2011. Cell counts were available for more than half of the HIV cases reported in $19 \mathrm{EU} / \mathrm{EEA}$ countries. Among those, $49 \%$ were reported with a CD4 cell count $3350 / \mathrm{mm}^{3}$, including $29 \%$ of cases with a CD4 cell count $<200 /$ $\mathrm{mm}^{3}$, categorised as advanced HIV infection. By transmission mode, the highest proportion of cases with $\mathrm{CD}_{4}<350 / \mathrm{mm}^{3}$ was observed among heterosexually acquired cases, especially among those originating from sub-Saharan Africa (63\%). The lowest proportion of cases with $\mathrm{CD}_{4}<350 / \mathrm{mm}^{3}$, as well as those with $\mathrm{CD}_{4}$ $<200 / \mathrm{mm}^{3}$, was observed among cases due to motherto-child transmission ( $21 \%$ and $14 \%$, respectively) and MSM (38\% and 19\%, respectively) (Figure 4 ).

\section{Conclusions}

HIV surveillance data show that the population of people living with HIV in the EU/EEA is increasing due to effective and widely available treatment and due to the number of new HIV diagnoses reported annually. HIV continues to be highly concentrated in specific populations, such as MSM, IDU and persons originating from sub-Saharan African countries. Although there is an apparent decline in the number of HIV diagnoses among IDU, substantial numbers of HIV diagnoses were reported in the Baltic States and recent outbreaks of HIV infection in Greece and Romania signal the potential for rapid spread of HIV among IDU [4-8].

Interventions to control the HIV epidemic need to be adapted to the national epidemiological situation. In the EU/EEA, the prevention and control of HIV infection among MSM is the cornerstone of the HIV response. In addition, as a third of the heterosexual HIV cases were reported in people from sub-Saharan Africa with a generalised HIV epidemic, countries need to ensure that treatment and care are accessible to these migrant populations. The observed increase in the number of HIV cases among IDU in a number of countries demonstrates the importance of maintaining or scaling up of harm reduction interventions in the EU/EEA.

It is of concern that half of the HIV cases with information on $\mathrm{CD}_{4}$ cell counts are diagnosed with a low count, when individuals are already eligible for treatment. It is of equal concern that the number of AIDS diagnoses is increasing in a number of countries despite the widespread availability of effective antiretroviral therapy. Delayed start of lifesaving HIV treatment decreases the clinical benefits, as well as the preventive value of the treatment in terms of further HIV transmission. HIV counselling and testing need to be promoted to ensure earlier diagnosis, access and adherence to treatment that will in turn result in the reduction of transmission. Equal access to HIV treatment and care for all should be ensured by countries, to sustain high quality of life 
of citizens and to reach the (inter)national commitments even in times of economic austerity.

\section{Acknowledgements}

We would like to thank National HIV Contact Points from countries participating in the European network for HIV/ AIDS surveillance: Austria: Klein Jean Paul; Belgium: Andre Sasse; Bulgaria: Tonka Varleva; Cyprus: Avgi Hadjiloukas; Czech Republic: Marek Maly; Denmark: Susan Cowan; Estonia: Kristi Rüütel; Finland: Kirsi Liitsola; France: Caroline Semaille; Germany: Osamah Hamouda; Greece: Georgios Nikolopoulos, Dimitra Paraskeva; Hungary: Mária Dudás; Iceland: Haraldur Briem; Ireland: Derval Igoe; Italy: Barbara Suligoi; Latvia: Šarlote Konova; Lithuania: Saulius Čaplinskas; Luxembourg: Jean Claude Schmit; Malta: Jackie Maistre Melillo; Netherlands: Eline op de Coul; Norway: Hans Blystad; Poland: Magdalena Rosinska; Portugal: Helena Cortes Martins; Romania: Mariana Mardarescu; Slovakia: Peter Truska; Slovenia: Irena Klavs; Spain: Mercedes Diez Ruiz-Navarro; Sweden: Frida Hansdotter; United Kingdom: Valerie Delpech. We would like also to thank ECDC colleagues for their contributions, especially Chantal Quinten, the TESSy team and Valentina Lazdina.

\section{References}

1. European Centre for Disease Prevention and Control (ECDC)/ WHO Regional Office for Europe. HIV/AIDS surveillance in Europe 2011. Stockholm: ECDC; 2012. Available from: http:// ecdc.europa.eu/en/publications/Publications/20121130Annual-HIV-Surveillance-Report.pdf

2. European Centre for Disease Prevention and Control (ECDC)/ WHO Regional Office for Europe. HIV/AIDS surveillance in Europe 2010. Stockholm: ECDC; 2011. Available from: http:// www.ecdc.europa.eu/en/publications/Publications/111129_ SUR_Annual_HIV_Report.pdf

3. European Centre for Disease Prevention and Control (ECDC)/ WHO Regional Office for Europe. HIV/AIDS surveillance in Europe 2009. Stockholm: ECDC; 2010.

4. Paraskevis D, Nikolopoulos G, Tsiara C, Paraskeva D, Antoniadou A, Lazanas M, et al. A. HIV-1 outbreak among injecting drug users in Greece, 2011: a preliminary report. Euro Surveill. 2011;16(36):pii=19962. Available from: http://www. eurosurveillance.org/ViewArticle.aspx?Articleld=19962

5. Hellenic Center for Disease Control and Prevention (HCDCP). HIV/AIDS surveillance report in Greece, 31-12-2011 (Issue 26). Athens: HCDCP; 2011. Available from: http://www.keelpno.gr/ Portals/o/\%CE\%91\%CF\%81\%CF\%87\%CE\%B5\%CE\%AF\%CE \%B1/HIV/EPIDIMIOLOGIKO\%20HIV_2011.pdf

6. Fotiou A, Micha K, Paraskevis D, Terzidou M, Malliori M, Hatzakis A. HIV outbreak among injecting drug users in Greece. An updated report for the EMCDDA on the recent outbreak of HIV infections among drug injectors in Greece. 31 October 2012. Athens: REITOX Focal Point of the EMCDDA-Greece; 2012. Available from: http://www.emcdda.europa.eu/attachements. cfm/att_191984_EN_HIV_update_Greece_2012.pdf

7. Pharris A, Wiessing L, Sfetcu O, Hedrich D, Botescu A, Fotiou $A$, et al. Human immunodeficiency virus in injecting drug users in Europe following a reported increase of cases in Greece and Romania, 2011. Euro Surveill. 2011;16(48):pii=20032. Available from: http://www.eurosurveillance.org/ViewArticle. aspx?Articleld $=20032$

8. European Centre for Disease Prevention and Control (ECDC). Risk assessment on HIV in Greece. Stockholm: ECDC; 2012. Available from: http://ecdc.europa.eu/en/publications/ Publications/20121130-Risk-Assessment-HIV-in-Greece.pdf 